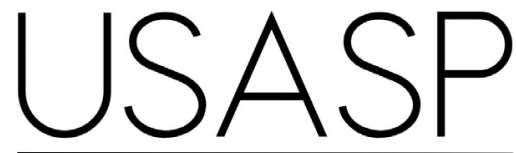

US ASSOCIATION FOR THE STUDY OF PAIN

\title{
Investigating the True Effect of Psychological Variables Measured Prior to Arthroplastic Surgery on Postsurgical Outcomes: A P-Curve Analysis
}

\author{
Nils Georg Niederstrasser, * and Stephanie Cook ${ }^{\dagger}$ \\ * Department of Psychology, University of Portsmouth, Portsmouth, UK \\ † School of Applied Social Sciences, De Montfort University, Leicester, UK
}

\begin{abstract}
Patients' presurgical psychological profiles have been posited to predict pain and function following arthroplastic surgery of the hip and knee. Nevertheless, findings are conflicting, and this may be rooted in biased reporting that makes the determination of evidential value difficult. This ambiguity may have negative consequences for researchers and governmental agencies, as these rely on findings to accurately reflect reality. $P$-Curve analyses were used to establish the presence of evidential value and selective reporting in a sample of studies examining the effect of presurgical psychological predictors on outcomes following knee and hip arthroplastic surgery. A systematic search of the literature revealed 26 relevant studies. The examined sets of studies indicate that there is evidential value for the effect of depression on pain intensity and function, anxiety on pain intensity and function, pain catastrophizing on pain intensity, as well as the combined effects of all psychological predictors on pain intensity and function. The presence of evidential value was inconclusive for the effect of optimism on pain intensity. There were no signs that any results were influenced by biased reporting. The results highlight the importance of patients' psychological profiles in predicting surgical outcomes, which represent a promising avenue for future treatment approaches.

Perspective: The effects of $P$-hacking are difficult to detect and might be at the root of conflicting findings pertaining to the predictive properties of presurgical psychological variables on postsurgical outcomes. $P$-Curve analysis allows the determination of evidential value underlying these relationships and detection of $\boldsymbol{P}$-hacking to ensure that findings are not the result of selective reporting.

○ 2020 by United States Association for the Study of Pain, Inc.

Key Words: P-Curve, arthroplasty, depression, optimism, anxiety, function, postsurgical pain, pain catastrophizing.
\end{abstract}

$\mathrm{O}$ steoarthritis $(O A)$ is a chronic pain condition that affects roughly 8.75 million people in the UK, with the knee and hip being the most commonly affected sites. ${ }^{2}$ Although arthroplasty is considered an effective treatment and, in many cases, a cure for chronic OA-pain, almost $30 \%$ of patients undergoing knee or hip replacement surgery develop increased pain and disability, despite objective indicators of

Received August 19, 2019; Revised July 2, 2020; Accepted July 31, 2020 Disclosures: The authors have no financial interest in the results of this research and report no conflict of interest.

Address reprint requests to Nils Niederstrasser, $\mathrm{PhD}$, Senior Lecturer in Psychology, Faculty of Science and Health, Department of Psychology, University of Portsmouth, Portsmouth PO1 2DY UK E-mail: nils niederstrasser@port.ac.uk

$1526-5900 / \$ 36.00$

๑ 2020 by United States Association for the Study of Pain, Inc.

https://doi.org/10.1016/j.jpain.2020.07.005 surgical success. ${ }^{7,17,51}$ Patients' presurgical psychological profiles may play a major role in determining the longterm efficacy of surgery by affecting the recovery process. ${ }^{13,32,40,45,59,60,68,78-80}$ Specifically, preoperative levels of fear of pain, ${ }^{41,79}$ pain catastrophizing, ${ }^{22,80,87}$ depression, ${ }^{11,20,63,64,68}$ optimism, ${ }^{55}$ self-efficacy, ${ }^{18,86,88}$ kinesiophobia, $^{20}$ and anxiety ${ }^{6,20}$ have been suggested to explain some of the variability in outcomes, such as pain intensity and function, following arthroplasty and may represent promising avenues for future interventions. Nevertheless, there is considerable heterogeneity in these findings, which has cast doubt onto the presence of true effects. ${ }^{40,87}$ For example, numerous studies report evidence for the influence of presurgical depressive symptoms on outcomes following arthroplasty, for example, ${ }^{11,20,63,64,68}$ while others, for example, ${ }^{48,59,60,80}$ report the absence of such effects. 


\section{The Journal of Pain}

Aside from methodological differences, such conflicting results may be in part due to publication bias and selective reporting, ${ }^{36,70,82}$ which increase the odds of publishing results falsely supporting researchers' hypotheses. ${ }^{36,82}$ Intuitively, for each published falsepositive result, there should be an even greater number of true-negative results. Conversely, for each false-negative finding, there should be an exceeding number of true-positive results, thus creating a protective ratio of true published findings that adequately represents reality..$^{70}$ While seemingly attractive, this notion fails when studies are inadequately powered, not all studies are published, and when researchers engage, willingly or naively, in problematic practices, commonly referred to as $p$-hacking. ${ }^{25,30,70-72}$ When decisions researchers are forced to make in the process of collecting, analyzing, and reporting data are not specified in advance, but rather on the fly, researchers may be biased towards making these decisions to serve their chances of publication. ${ }^{43,70}$ For example, in the hopes of results reaching statistical significance, researchers may choose to collect more data or attempt analyses with and without certain covariates or outliers. This differs from publication bias, which may also be due to people other than the author, such as editors, reviewers, or publishers. p-Hacking, greatly increases the likelihood of reporting false-positive and thus, nonexistent findings. ${ }^{69}$ With this in mind, the notion of a protective ratio of true-negative to false-positive findings becomes implausible. ${ }^{62}$

As a consequence of $p$-hacking, the probability of falsepositive findings increases relative to the probability of true-positives. This is problematic, as funding bodies and governmental agencies may make decisions based on published evidence that does not represent reality, that is, has no evidential value, and researchers may futilely attempt to investigate or reproduce nonexistent effects. ${ }^{70}$ Thus, the presence of evidential value, and selective reporting regarding the effect of presurgical psychological variables in predicting outcomes from arthroplasty should be determined. Then, based on the presence of evidential value, further developments aimed at improving the efficacy of arthroplasty and reducing the considerable pain associated with $O A^{5}$ by improving patients' presurgical psychological profiles can be implemented.

$P$-Curve analysis ${ }^{70}$ has emerged as a tool to establish the existing evidential value and identify instances of $P$ hacking. In $P$-curve analysis, the distribution of reported statistically significant $P$ values allows researchers to determine whether selective reporting or true effects are present. In this way, $P$-curve analysis differs from meta-analyses. ${ }^{71}$ Here, we use $P$-curve analysis to establish the presence or absence of evidential value and selective reporting using preregistered study criteria and methods in a sample of studies examining the effect of presurgical psychological predictors on outcomes following knee and hip arthroplastic surgery.

\section{Methods}

The study and $P$ value selection criteria were finalized on November 7, 2018 and preregistered on www.
A p-Curve Analysis

aspredicted.org alongside the study's hypotheses and can be found here: https://aspredicted.org/394si.pdf.

\section{Study Selection and Search Criteria}

To be considered for inclusion in the $P$-curve analysis a study's hypothesis had to specifically state it was aimed at examining the predictive properties of at least one psychological variable measured prior to surgery on at least one postsurgical outcome. Presurgical psychological predictors of interest were limited to pain catastrophizing, fear of pain, mood, self-efficacy, kinesiophobia, depression, and anxiety; and postsurgical outcomes to pain intensity, consumption of analgesic medication, physical function, quality of life, and mood. The surgery of interest was replacement (arthroplasty) of the hip or knee. Several inclusion criteria were applied: 1) only peer-reviewed studies written in English were included; 2) participants must be generally healthy adults, undergoing any type of knee or hip replacement surgery and not suffering from any other physical disorders; 3) studies must be prospective in nature and evaluate the effect of one or multiple presurgical psychological predictors on one or multiple postsurgical outcomes; 4) predictors must be measured prior to surgery. Exclusion criteria were as follows: 1) studies examining a range of surgical interventions (ie, not arthroplasty of the hip or knee) and not differentiating the results of each group; 2 ) case studies; 3 ) studies examining the effects of interventions; 4) studies examining or not separating effects of participants undergoing unsuccessful surgeries. In the case of duplicate publications or publications that used the same set of patient data, only the most complete paper was included, or the first publication if patient numbers were identical. As only published papers were of interest, the gray literature was not searched.

Medline (PubMed) and PsycINFO (proquest) databases were searched using the terms: catastroph*, kinesiophob*, fear, mood, depress*, anxi*, self-efficacy, optimism, pessimism, arthropl*, knee replacement, hip replacement, TKJR, TKA, TKR, and THA. A total of 1,517 individual manuscripts were identified and subsequently reviewed independently by authors N.N. and S.C. Following this initial review, 46 full-texts were assessed for eligibility of which 20 manuscripts were excluded for at least one of the following reasons: nonsignificant findings $(n=6), 1,10,48,56,58,63$ the analyses/ results were not relevant to review hypotheses $(n=6),{ }^{6,9,20,35,42,90}$ and the critical test statistic was not reported, could not be computed based on reported data, and could not be obtained after contact with the author $(n=3)^{3,18,86}$ (see Fig 1). The latter criterion included studies reporting $P$-value ranges (eg, $P<.05$ ) in the absence of data allowing the computation of critical test statistics or exact $P$-values. Inclusion of $P$ value ranges would render the shape of the $P$-curve unreliable and such values were therefore excluded. In the case of multiple available $P$ values, the values highest in the selection hierarchy were examined and if they were not suitable, the entire study was excluded. ${ }^{70-72}$ Five other studies were excluded because they used the same 


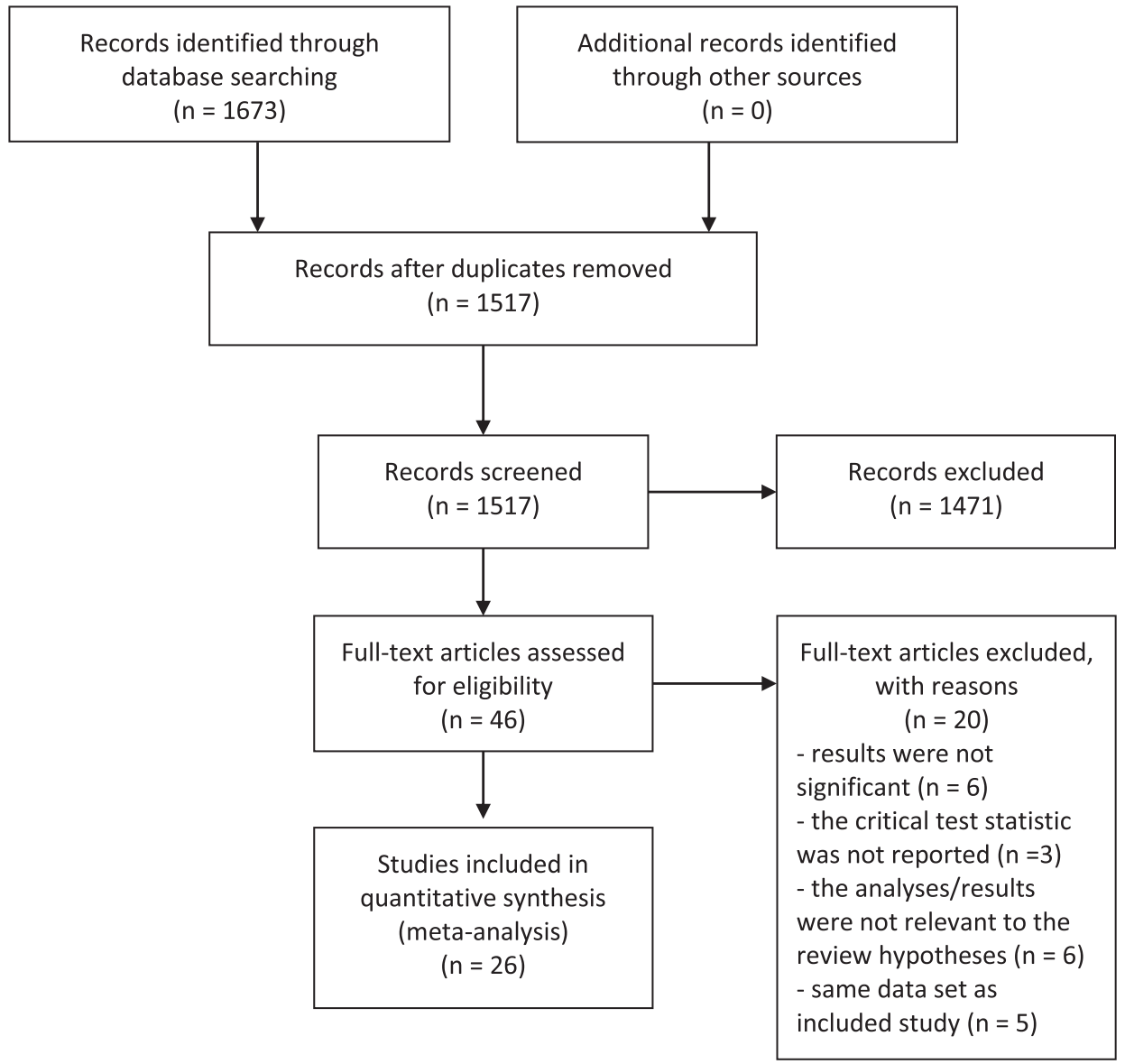

Figure 1. PRISMA 2009 flow diagram, overview of included and excluded studies.

dataset as another study by the same author that was included in the analysis, but was less complete (fewer participants), ${ }^{73,75,89}$ or in case of identical patient numbers was published after the included study. ${ }^{74,79}$ Thus, data from 26 studies were included in the analyses.

\section{P Value Selection}

$P$ values associated with analyses that examine the predictive properties of psychological variables measured prior to surgery on postsurgical outcomes from relevant studies were selected. If more than one adequate $P$ value was found in a study, the $P$ value belonging to the analysis examining the postsurgical outcome closest to 6 months after surgery was selected. For example, in a case where there were 2 results examining whether pain catastrophizing predicts pain intensity at 1 month and 7 months after surgery, the $P$-value belonging to the analysis for 7 months postsurgery was selected. In the case of more than one relevant analysis (eg, correlations and linear regression or univariate and multivariate regressions) the following hierarchy for the selection of $P$ values was applied: 1 ) regression - with covariates; 2 ) regression - without covariates; 3 ) other.
In the case of "other", the first relevant $P$-value that was encountered in the first relevant table was used. In the case of odds ratios with categorical predictors, the first comparison reported in the corresponding table was used. All $P$ values were recomputed, as per the recommendations by Simonsohn et al. ${ }^{70}$

During the $P$ value extraction we followed the guidelines stipulated by, ${ }^{70}$ which further outline when to include interaction effects, linear trends, or simple effects, based on the type of statistical test employed in the respective study. Following these guidelines, a $P$-curve disclosure table was completed (see Table 1), comprising of original text quoted from the included manuscripts delineating study design, key statistical results (including a quotation), type of surgery, study quality, and the quantitative results as included in the $P$-curve analysis as well as, where applicable, robustness results. Only significant results were recorded in the P-curve disclosure table.

\section{P-Curve Analyses}

We conducted a total of $9 P$-curve analyses. In the case of multiple values extracted from the same study, the 
Table 1. $P$-curve Disclosure Table

\section{ORIGINAL PAPER JOURNAL ISSUE QUOTED TEXT}

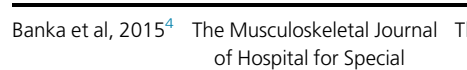

Of Hospital for Spery, 11
Surger

The aims of this study were to identify whether patient- Prospective cohort TKA

study

specific preoperative predictors inclualing preoperative

WOMAC pain score and visual analogue pain scale

(VAS) catastrophizing pain scores were predictive of

mestoperative pain scores, referral to pain manage-

$\begin{array}{cc}\text { Brander et al, } & \text { Clinical Orthopaedics and } \\ 2007^{11} & \text { Related Research, } 464\end{array}$

Brembo et al, Health and Quality of Life The overall aim was to determine whether perceived

Duivenvoorden et Osteoarthritis and Cartilage, To examine the prevalence of anxiety and depressive
symptoms in patients undergoing primary THA or TKA

Hirschmann et al, Knee Surgery, Sports Trau- The purpose was to investigate if preoperative psycho-

Judge et al, Rheumatology, 12 The primary aim of this study was to identify whether

Kagan et al, Journal of Clinical Nursing, This study examined the effect of preoperative anxiety $(464)$

We previously reported preoperative depression, anxiety, and pain were associated with greater pain, more utili-
zation of healthcare resources, and worse outcome 1 zation of healthcare resources, and worse outcome 1 year after total knee arthroplasty. We asked whether these outcomes persisted over time and whether patients with unexplained heightened pain early after surgery were ultimately satisfied.

$2017^{12} \quad$ Outcomes, 68 social support and general self-efficacy contribute to the variability in short-term postoperative recovery in sample of OA patients who have undergone THR. symptoms in patients undergoing primary THA or TKA preoperatively and postoperatively, and the relation-
ship between preoperative anxiety and depressive ship between preoperative anxiety and
symptoms on PROs of THA and TKA.

Faller et al, $2003^{19}$ General Hospital Psychiatry, The aim of this study was to determine whether patients Prospective study TKA $\begin{array}{ll}25 & \text { who were psychologically distressed at baseline had } \\ \text { worse outcomes regarding physical role limitations }\end{array}$ during household and work activities at both 3 and 12 during household and work activities at ba)

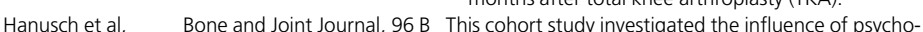
$\begin{array}{lll}2014^{29} & \text { (2) } & \text { logical factors, including perception of illness, anxiety } \\ \text { and depression on recovery and functional outcome }\end{array}$ matology, Arthroscopy, logical factors influence the subjective and objective . A of psychological factors patients' pre-operative characteristics can predic Ox Oxord Knee Score (OKS)] 6 months after surgery in a

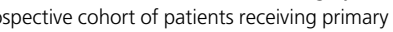
TKR in the UK National Health Service (NHS). and uncertainty on short-term physical and menta recovery after elective arthroplasty.

Prospective, longi- TKA tudinal, singlecohort study

Prospective study THR Prospective study THA

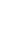

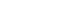
(statistical results do not appear in text).
In hip and knee patients, preoperative depressive symp-
toms predicted smaller changes in different HOOS or

loms predicted smaller changes in different HOOS or
KOOS subscales and patients were less satisfied 12
months postoperatively. (statistical results do not

toms predicted smaller changes in different H HOOS or
KOOS subscales and patients were less satisfied 12
months postoperatively. (statistical results do not appear in text)

Preoperative pain and depressive symptoms predicted lower KSS at 5 years $(P=.0003$ and .0004 , respectively) mainly as a consequence of worse function. Surprisingly, preoperative pain and depression did no predict a lower pain component but did predict a lower function component score at 5 years $(P=.015$ and .0004 , respectively).

By contrast, self-efficacy and reliable alliance appeared to Self-efficacy $\rightarrow$ Function be significant predictors even after adjusting for age, number of comorbidities, and preoperative WOMAC

When predicting the 3-months Function index, the beta weight of baseline psychological distress was .25 $(P=.032)$, after adjusting for the
index beta $=.58, P=<.001)$.

Prospective cohort TKA study

Prospective, longi- TKA

The HADS variable depression was also correlated with OKS at 6 weeks $(P=.003)$ and entered into a separate
OKS OKS at 6 weeks $(P=.003)$ and
multiple regression analysis.

More depressed patients showed higher postoperative WOMAC scores. Patients with higher trait anxiety after the operation (statistical results do not appear in text)

Prospective longi- TKR

tudinal cohort

study

Specifically for pain, patients with a diagnosis of $R A$ had $D$ better outcomes compared with those with primary $\mathrm{OA}$, and people with anxiety/depression had worse outcomes. (Moderately depressed/anxious (reference Not anxious/depressed) $\rightarrow$ Pain: OR $=.67,95 \% \mathrm{Cl}=$ .54-.84); (Moderately depressed/anxious (reference Not anxious/der
$=61,97)$

QuaziTKATTHA

Both preoperative anxiety and uncertainty were negatively related to all postoperative recovery variables except subjective readiness to be
cal results do not appear in text)

Depression was also found to be significantly correlated Depression $\rightarrow$ Function pression $\rightarrow$ Pain Anxiety $\rightarrow$ Pain Depression $\rightarrow$ QOL
Anxiety $\rightarrow$ QOL Depression $\rightarrow$ Pain Anxiety $\rightarrow$ Pain Depression $\rightarrow$ QOL

Depression $\rightarrow$ Function

Depression $\rightarrow$ Pain

Anxiety $\rightarrow$ Pain

Depression $\rightarrow$ Function

Anxiety $\rightarrow$ Function

Depression $\rightarrow$ Pain

Depression $\rightarrow$ Function

Anxiety $\rightarrow$ Pain

Anxiety $\rightarrow$ Function

$t(79)=3.688$

-exp

This study aims to define the determinants affecting
post-operative midterm active flexion according to a post-operative midterm active flexion according to
specific cruciate-sacrificing prosthesis, the rotating specific cruciate-sacrificing prosth
concave-convex $\left(\right.$ ROCC $\left.^{\circledR}\right)$ TKA. with post-AF (coefficient $-4.4 \pm 1.2, P<.001$ ).

Prospective study TKA $\begin{aligned} t(145) & =-3.497 \quad 13 \\ t(145) & =-2.714 \\ t(145) & =-2.756 \\ t(145) & =-3.18 \\ t(133) & =-2.799 \\ t(133) & =-2.111 \\ t(133) & =-2.041 \\ t(57) & =2.185 \\ t(57) & =2.185\end{aligned}$

$t(92)=1.986$

13

$r(102)=0.29$

$r(102)=0.25$

$r(102)=0.25$

$z=-3.553$

$Z=-2.209$
$Z=-3.639$

$\mathrm{Z}=-2.209$

12

$t(84)=2.66$ 23(6) 


\section{Table 1. Continued}

\begin{tabular}{|c|c|c|c|c|c|c|c|c|}
\hline ORIGINAL PAPER & JOURNAL ISSUE & QUOTED TEXT INDICATING PREDICTION OF INTEREST & STUDY DESIGN & $\begin{array}{l}\text { TYPE OF } \\
\text { SURGERY }\end{array}$ & QUOTED TEXT WITH STATISTICAL RESULTS & PREDICTOR $\rightarrow$ OUTCOME & RESULTS & StUdY QUALITY \\
\hline $\begin{array}{l}\text { Lindner et al, } \\
2018^{46}\end{array}$ & $\begin{array}{l}\text { BMC Musculoskeletal Disor- } \\
\text { ders, 19(1) }\end{array}$ & $\begin{array}{l}\text { As findings regarding predictors for good outcome after } \\
\text { total joint arthroplasty are highly inconsistent, aim of } \\
\text { this study was to investigate the influence of the psy- } \\
\text { chosocial variables sense of coherence and social sup- } \\
\text { port as well as mental distress on physical outcome } \\
\text { after surgery. }\end{array}$ & Prospective study & $\begin{array}{l}\text { THAVTKA (sig- } \\
\text { nificant } \\
\text { results for } \\
\text { THA only) }\end{array}$ & $\begin{array}{l}\text { In THA, 12-weeks WOMAC scores were predicted by } \\
\text { baseline measures of psychosocial aspects (anxiety, } \\
\text { sense of coherence, social support). (statistical results } \\
\text { do not appear in text) }\end{array}$ & $\begin{array}{l}\text { Anxiety } \rightarrow \text { Pain } \\
\text { Anxiety } \rightarrow \text { Function }\end{array}$ & $\begin{aligned} t(38) & =3.11 \\
t(38) & =3.69\end{aligned}$ & 14 \\
\hline $\begin{array}{l}\text { Lopez-Olivo et al., } \\
2011^{47}\end{array}$ & $\begin{array}{l}\text { Clinical and epidemiological } \\
\text { research, } 70(10)\end{array}$ & $\begin{array}{l}\text { The objective of this study was to identify potential psy- } \\
\text { chosocial and educational barriers to surgical success } \\
\text { following knee replacement. }\end{array}$ & $\begin{array}{l}\text { Prospective cohort } \\
\text { study }\end{array}$ & TKR & $\begin{array}{l}\text { Worse WOMAC function scores were associated with } \\
\text { less tangible support, depression and decreased prob- } \\
\text { lem-solving coping }(\mathrm{R} 2=.19) \text {. (statistical results do not } \\
\text { appear in text) }\end{array}$ & Depression $\rightarrow$ Function & $\mathrm{t}(225)=2.343$ & 15 \\
\hline $\begin{array}{l}\text { McHugh et al, } \\
2013^{50}\end{array}$ & Bone Joint Research, 2(11) & $\begin{array}{l}\text { The overall aim of this study was to investigate the bio- } \\
\text { medical and psychosocial outcomes following THR in } \\
\text { patients with OA and to determine which predictors } \\
\text { are associated with better outcomes of recovery from } \\
\text { THR. }\end{array}$ & Prospective study & THR & $\begin{array}{l}\text { In addition to the expected relationship with the preop- } \\
\text { erative Total Physical Score }(P<.001) \text {, change in Total } \\
\text { Physical Score at } 6 \text { months was significantly and nega- } \\
\text { tively associated with baseline HADS anxiety and } \\
\text { depression scores and WOMAC pain score at baseline } \\
(P=.034, P=.001 \text { and } P<.001 \text {, respectively). (statisti- } \\
\text { cal results do not appear in text) }\end{array}$ & $\begin{array}{l}\text { Anxiety } \rightarrow \text { Function } \\
\text { Depression } \rightarrow \text { Function }\end{array}$ & $\begin{aligned} t(183) & =2.136 \\
t(183) & =3.344\end{aligned}$ & 15 \\
\hline $\begin{array}{l}\text { Noiseux et al, } \\
2014^{52}\end{array}$ & $\begin{array}{l}\text { The Journal of Arthroplasty, } \\
\text { 29(7) }\end{array}$ & $\begin{array}{l}\text { Do high patient scores on scales of psychological state } \\
\text { prior to TKA, such as depression, anxiety and pain cat- } \\
\text { astrophizing, predict pain intensity ratings after total } \\
\text { knee? }\end{array}$ & $\begin{array}{l}\text { Prospective cohort } \\
\text { study }\end{array}$ & TKA & $\begin{array}{l}\text { Anxiety was the other variable found to be significant in } \\
\text { the postoperative multifactor analysis, with an odds } \\
\text { ratio of } 1.40 \text {. }\end{array}$ & Anxiety $\rightarrow$ Pain & $Z=2.6120$ & 12 \\
\hline Pinto et al., $2015^{53}$ & $\begin{array}{l}\text { Annals of Behavioral Medi- } \\
\text { cine, } 49(3)\end{array}$ & $\begin{array}{l}\text { The aims of this study are to identify psychological pre- } \\
\text { dictors of post-surgical pain following abdominal hys- } \\
\text { terectomy (AH) and major joint arthroplasty (MJA) and } \\
\text { to investigate differential predictors by type of surgery. }\end{array}$ & $\begin{array}{l}\text { Prospective cohort } \\
\text { study }\end{array}$ & TKA/THA & $\begin{array}{l}\text { Optimism was added as the last block, constituting a sig- } \\
\text { nificant predictor (t(103)=-3.461, } \beta=-.297 \text {, } \\
P=.001) \text {. }\end{array}$ & Optimism $\rightarrow$ Pain & $t(114)=-3.461$ & 14 \\
\hline Pinto et al, $2013^{55}$ & Journal of Pain, 14(5) & $\begin{array}{l}\text { This study aims to examine the joint role of demographic, } \\
\text { clinical, and psychological variables as predictors of } \\
\text { acute postsurgical pain and anxiety in patients under- } \\
\text { going total knee arthroplasty and total hip } \\
\text { arthroplasty }\end{array}$ & $\begin{array}{l}\text { Prospective cohort } \\
\text { study }\end{array}$ & TKAЛTHA & $\begin{array}{l}\text { Optimism was the only significant predictor of pain in the } \\
\text { final regression model }(b=.24, P=.008) \text {. }\end{array}$ & Optimism $\rightarrow$ Pain & $\mathrm{t}(119)=-2.716$ & 14 \\
\hline Pinto et al, $2017^{54}$ & Journal of Pain Research, 10 & $\begin{array}{l}\text { This study aims to compare acute postsurgical pain inten- } \\
\text { sity, and its potential predictors, between two types of } \\
\text { major joint arthroplasties: THA and TKA. }\end{array}$ & $\begin{array}{l}\text { Prospective longi- } \\
\text { tudinal cohort } \\
\text { study }\end{array}$ & $\begin{array}{l}\text { TKA/THA (sig- } \\
\text { nificant } \\
\text { results for } \\
\text { TKA only) }\end{array}$ & $\begin{array}{l}\text { In the final model, optimism was the only significant pre- } \\
\text { dictor of pain (t[51] }=-2.518, \beta=-.339, P=.015) \text {. }\end{array}$ & Optimism $\rightarrow$ Pain & $t(53)=-2.518$ & 13 \\
\hline $\begin{array}{l}\text { Riddle et al, } \\
2010^{60}\end{array}$ & $\begin{array}{l}\text { Clinical Orthopaedics and } \\
\text { Related Research, 468(3) }\end{array}$ & $\begin{array}{l}\text { We therefore asked whether either psychologic disorders } \\
\text { or pain-related beliefs could predict either pain or } \\
\text { physical function outcome after knee arthroplasty. }\end{array}$ & $\begin{array}{l}\text { Prospective longi- } \\
\text { tudinal cohort } \\
\text { study }\end{array}$ & TKA & $\begin{array}{l}\text { Pain intensity: For WOMAC pain, only the dichotomized } \\
\text { PCS score (odds ratio [OR], 2.67; } 95 \% \text { confidence } \\
\text { interval [CI], } 1.2-6.1) \text { predicted improvement by the } \\
\text { less than } 50 \% \text { poor outcome criterion after adjust- } \\
\text { ment for potential confounders. } F=5.47, P=.02 \text {. }\end{array}$ & Catastrophizing $\rightarrow$ Pain & $F(1,134)=5.47$ & 14 \\
\hline $\begin{array}{l}\text { Rolfson et al, } \\
2009^{61}\end{array}$ & $\begin{array}{l}\text { The Journal of Bone and } \\
\text { Joint Surgery, } 91(2)\end{array}$ & $\begin{array}{l}\text { In this study we used subjects in the Swedish registry to } \\
\text { examine the hypothesis that anxiety/ depression (one } \\
\text { of the five dimensions of the EQ-5D) is a significant } \\
\text { variable in predicting satisfaction and pain relief after } \\
\text { THR. }\end{array}$ & $\begin{array}{l}\text { Prospective longi- } \\
\text { tudinal cohort } \\
\text { study }\end{array}$ & THA & $\begin{array}{l}\text { Adjusting for all dimensions of EQ-5D preoperatively, } \\
\text { Charnley category, age and gender, multivariate linear } \\
\text { regression analysis showed that the degree of pain } \\
\text { relief and satisfaction } 1 \text { year after surgery were related } \\
\text { to preoperative anxiety/depression in the fifth EQ-5D } \\
\text { dimension and reduction of the Charnley category. } \\
\text { (statistical results do not appear in text) }\end{array}$ & $\begin{array}{l}\text { Anxiety } \rightarrow \text { Pain } \\
\text { Depression } \rightarrow \text { Pain }\end{array}$ & $\begin{array}{c}t(6149)=-5.166 \\
t\end{array}$ & \\
\hline $\begin{array}{l}\text { Salmon et al, } \\
2001^{64}\end{array}$ & $\begin{array}{l}(6149)=-5.166 \\
\text { Journal of Behavioral Medi- } \\
\text { cine, 24(5) }\end{array}$ & $\begin{array}{l}13 \\
\text { The present study therefore examined the relationship of } \\
\text { perioperative emotional state to functional recovery } \\
\text { from hip arthroplasty, using reliable and validated } \\
\text { measures of postoperative recovery which were also } \\
\text { used to control for preoperative function. }\end{array}$ & $\begin{array}{l}\text { Prospective longi- } \\
\text { tudinal cohort } \\
\text { study }\end{array}$ & THA & $\begin{array}{l}\text { In the analysis of WOMAC at } 6 \text { months, preoperative } \\
\text { WOMAC was again significant. From the POMS varia- } \\
\text { bles entered in the second block, preoperative fatigue } \\
\text { was significant beta } .25, P<.01, b=83,(C I .20,1.47) \text {. }\end{array}$ & Mood $\rightarrow$ Function & $t(98)=2.594$ & 14 \\
\hline
\end{tabular}




\section{Table 1. Continued}

\begin{tabular}{|c|c|c|c|c|c|c|c|c|}
\hline ORIGINAL PAPER & JOURNAL ISSUE & QUOTED TEXT INDICATING PREDICTION OF INTEREST & STUDY DESIGN & $\begin{array}{l}\text { TYPE OF } \\
\text { SURGERY }\end{array}$ & QUOTED TEXT WITH STATISTICAL RESULTS & $P_{\text {REDICTOR } \rightarrow \text { OUTCOME }}$ & RESULTS & STUDY QUALITY \\
\hline $\begin{array}{l}\text { Sanchez-Santos et } \\
\text { al, } 2018^{65}\end{array}$ & Scientific Reports, 8(1) & $\begin{array}{l}\text { Therefore, as an example application of clinical predic- } \\
\text { tion model, we developed and externally validated a } \\
\text { simple prediction model for improvement in pain and } \\
\text { function } 12 \text { months after TKR using data from the } \\
\text { Knee Arthroplasty Trial (KAT) 20,21 (development } \\
\text { dataset) and the Clinical Outcomes in Arthroplasty } \\
\text { study (COASt) (validation dataset). }\end{array}$ & Prospective study & TKA & $\begin{array}{l}\text { Worse preoperative OKS, self-reported anxiety/depres- } \\
\text { sion, presence of ASA grade } 3 / 4 \text { (compared to fit and } \\
\text { healthy), presence of other conditions affecting mobil- } \\
\text { ity and previous knee arthroscopy were strongly asso- } \\
\text { ciated with worse outcome. Beta }-1.6 \text { ( } \mathrm{Cl}=-2.5 \text { to } \\
-0.6), P=.001 \text {. }\end{array}$ & $\begin{array}{l}\text { Depression } \rightarrow \text { Pain } \\
\text { Depression } \rightarrow \text { Function } \\
\text { Anxiety } \rightarrow \text { Pain } \\
\text { Anxiety } \rightarrow \text { Function }\end{array}$ & $\begin{aligned} t(1636) & =3.29 \\
t(1636) & =3.29 \\
t(1636) & =3.29 \\
t(1636) & =3.29\end{aligned}$ & 13 \\
\hline Singh et al, $2012^{76}$ & $\begin{array}{l}\text { Arthritis Research \& Ther- } \\
\text { apy, } 14\end{array}$ & $\begin{array}{l}\text { We hypothesized that patient demographics and comor- } \\
\text { bidities will be associated with the use of pain medica- } \\
\text { tions after TKA. Specifically, we assessed whether } \\
\text { female gender, younger age, higher BMI, pre-opera- } \\
\text { tive medical comorbidities, depression and anxiety, } \\
\text { were associated with use of NSAIDs and opioid pain } \\
\text { medications at } 2 \text { and } 5 \text { years after TKA. }\end{array}$ & $\begin{array}{l}\text { Prospective longi- } \\
\text { tudinal cohort } \\
\text { study }\end{array}$ & TKA & $\begin{array}{l}\text { Presence of depression increased the odds of NSAID use } \\
\text { by 1.4, compared to those without depression. } \\
\text { (Depression (reference no depression) } \rightarrow \text { Analgesic } \\
\text { consumption: } \mathrm{OR}=1.39,95 \% \mathrm{Cl}=1.04-1.85 \text {, } \\
P=.03 \text { ) }\end{array}$ & Depression $\rightarrow$ Analgesic consumption & $Z=2.241$ & 12 \\
\hline $\begin{array}{l}\text { Sullivan et al, } \\
2009^{80}\end{array}$ & PAIN, 143 & $\begin{array}{l}\text { In the present study, patients scheduled for TKA were } \\
\text { assessed one week prior to surgery and then again 6- } \\
\text { weeks post-surgery. Analyses examined the value of } \\
\text { pre-surgical measures of pain catastrophizing, pain- } \\
\text { related fears of movement and depressive symptoms } \\
\text { in the prediction of postsurgical pain severity and } \\
\text { physical function. }\end{array}$ & $\begin{array}{l}\text { Prospective longi- } \\
\text { tudinal cohort } \\
\text { study }\end{array}$ & TKA & $\begin{array}{l}\text { Pre-surgical scores on measures of pain catastrophizing, } \\
\text { pain-related fears, and depression were significantly } \\
\text { correlated with postsurgical measures of pain and } \\
\text { function. }\end{array}$ & $\begin{array}{l}\text { Catastrophizing } \rightarrow \text { Pain } \\
\text { Anxiety } \rightarrow \text { Function }\end{array}$ & $\begin{aligned} Z & =4.1531 \\
& Z=3.3627\end{aligned}$ & 12 \\
\hline $\begin{array}{l}\text { Thomazeau et al, } \\
2016^{84}\end{array}$ & $\begin{array}{l}\text { European Journal of Pain } \\
\text { (United Kingdom), 20(5) }\end{array}$ & $\begin{array}{l}\text { In this prospective observational cohort study, we aimed } \\
\text { to identify the determinants of acute postoperative } \\
\text { pain intensity at rest and post-operative opioid } \\
\text { requirement in the context of multimodal analgesia, in } \\
\text { patients undergoing knee arthroplasty. }\end{array}$ & $\begin{array}{l}\text { Prospective longi- } \\
\text { tudinal cohort } \\
\text { study }\end{array}$ & TKA & $\begin{array}{l}\text { Mean postoperative opioid requirement ( } P<.001) \text {, HAD- } \\
\text { A score }(P=.001) \text {, DN4 score }(P=.030) \text { and preopera- } \\
\text { tive pain at rest }(P=.047) \text { were independently posi- } \\
\text { tively associated with mean postoperative pain at rest. }\end{array}$ & Anxiety $\rightarrow$ Pain & $t(94)=3.52$ & 13 \\
\hline $\begin{array}{l}\text { Wylde et al, } \\
2012^{88}\end{array}$ & Musculoskeletal Care, 10(2) & $\begin{array}{l}\text { The purpose of this study was to determine if self-effi- } \\
\text { cacy was a significant and independent preoperative } \\
\text { predictor of patient-reported pain and function at } 1 \\
\text { year after TKR. }\end{array}$ & $\begin{array}{l}\text { Prospective longi- } \\
\text { tudinal cohort } \\
\text { study }\end{array}$ & TKA & $\begin{array}{l}\text { In this model, self-efficacy contributed significantly to } \\
\text { explaining the variance in postoperative knee func- } \\
\text { tion, with worst scores predicting greater functional } \\
\text { limitations after TKR }(P=.024) \text {. (unstandardized } \\
\text { regression coefficient: }-.256) \text {. }\end{array}$ & $\begin{array}{l}\text { Anxiety } \rightarrow \text { Pain } \\
\text { Anxiety } \rightarrow \text { Function } \\
\text { Self-Efficacy } \rightarrow \text { Function }\end{array}$ & $\begin{aligned} \mathrm{t}(211) & =2.678 \\
\mathrm{t}(211) & =2.307 \\
\mathrm{t}(211) & =2.274\end{aligned}$ & 12 \\
\hline $\begin{array}{l}\text { Yakobov et al, } \\
2018^{91}\end{array}$ & $\begin{array}{l}\text { Health and Quality of Life } \\
\text { Outcomes, 16(1) }\end{array}$ & $\begin{array}{l}\text { The purpose of the present study was to determine the } \\
\text { value of presurgical pain catastrophizing in predicting } \\
\text { HRQoL judgments after TKA }\end{array}$ & $\begin{array}{l}\text { Prospective longi- } \\
\text { tudinal cohort } \\
\text { study }\end{array}$ & TKA & $\begin{array}{l}\text { Examination of the standardized beta weights from the } \\
\text { final regression equation indicated that only baseline } \\
\text { SF-12 PCS }(\beta=.37, P<.001) \text { and pain catastrophizing } \\
(\beta=-.35, P<.001) \text { contributed significant unique } \\
\text { variance to the prediction of postsurgical SF-12 PCS. }\end{array}$ & Catastrophizing $\rightarrow$ Pain & $t(115)=3.377$ & 12 \\
\hline
\end{tabular}

Kart

dataset.

spective longi- TKA

by 1.4, compared to those without depression.
(Depression (reference no depression) $\rightarrow$ Analge
consumption: $\mathrm{OR}=1.39,95 \% \mathrm{Cl}=1.04-1.85$.

fem a

tive medical comorbidities, depression and anxiety,

he present study, patients scheduled for TKA were

assessed one week prior to surgery and then again 6 -

weeks post-surgery. Analyses examined the value of

in the prediction of postsurgical pain severity and

his prospective observational cohort study, we aimed

to identify the determinants of acute postoperative

requirement in the context of multimodal analgesia, in

patients undergoing knee arthroplasty.

spective longi- TKA

tudinal cohort

tion, with worst scores predicting greater functional

11) $=2.678$

gression coefficient:- 256 ).

inal regression equation indicated that only baseline

$(\beta=-.35, P<.001)$ contributed significant unique

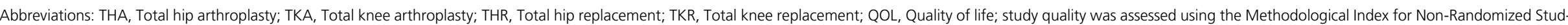
ies (MINORS), results out of 16; All values are limited to $3 \mathrm{dp}$. 
value mentioned first in the manuscript was selected. We ran additional $P$-curve analyses including the omitted values to examine the robustness of the findings. The first analysis comprised of data from all 26 included studies (27 $P$ values) and examined the evidential value of presurgical psychological predictors on function, well-being, analgesic consumption, and reported pain intensity following surgery. Some sets of studies were too small for individual $P$-curve analyses, that is, catastrophizing on function, self-efficacy on function, and anxiety on quality of life, depression on analgesic consumption, and pain catastrophizing on analgesic consumption, each set comprising of no more than 2 test statistics. These studies were, however, included in the overall analyses of psychological predictors on function and pain intensity where applicable. The remaining 8 analyses examined the evidential value underlying the following relationships between presurgical psychological factors and postsurgical outcomes: 2) presurgical psychological factors on function $(n=14), 3)$ presurgical psychological factors on pain intensity $(n=16), 4)$ depression on function $(n=9), 5)$ depression on pain intensity $(n=6), 6)$ anxiety on pain intensity $(n=10), 7)$ anxiety on function $(n=8)$, pain catastrophizing on pain intensity $(n=3)$, and 9$)$ optimism on pain intensity $(n=3$; see Table 1 for an overview and study details).

\section{Computing the P-Curves}

A detailed description of $P$-curve analysis can be found here. ${ }^{70-72}$ To conduct the $P$-curve analyses, we used the online $P$-curve app (version 4.06, www.p-curve. com/app4/). Test statistics, rather than $P$-values, were entered directly into the application alongside degrees of freedom (eg, $\mathrm{t}(211)=2.274)$. $p$-curve analysis examines the distribution of significant reported $P$ values $(P<$ $.05)$ and effectively tests whether 1$)$ there is evidential value ( $P$-curve is significantly right-skewed) or 2 ) the studies show inadequate, if any, evidential value $(P$ curve is found to be flatter compared to a $P$-curve comprised of studies powered at 33\%). Evidential value signifies whether reported significant results per se constitute evidence for the experimental hypothesis. In the case of a true effect (evidential value is present), the distribution of $P$-values is right-skewed, as it is more likely to contain lower $P$-values $(e g, .01)$ rather than high $P$-values $(\mathrm{eg}, 0.04)$. For a set of studies with no or inadequate evidential value the distribution of $P$-values is expected to be uniform, while intense $P$-hacking results in a left-skewed distribution of $P$ values (ie, more high than low $P$-values).

The nature of the distribution is quantified by the application through 2 continuous tests, the half (includes only values $P<.025$ ) and full $P$-curve (includes all $P$ values) tests, as well as a binomial test. In the case of the continuous tests, the likelihood of observing a $P$ value at least as extreme as the one entered ( $P$ value) is calculated in case there is no effect expected (test for right skew) and in case of the studies being powered at an average $33 \%$ (test for inadequacy of evidential value). Next, using Stouffer's method, the obtained results are aggregated. The binomial test involves calculating the proportion of $P$ values above and below .025 and comparing this proportion against the expected proportion in case there is no effect (50\%; test for right skew) or if the studies have $1 / 3$ power (roughly $71 \%$ depending on df of entered test statistics; test for inadequacy of evidential value).

Presence of evidential value is indicated when either 1$)$ the half $P$-curve test is right skewed $(P<.05)$ or 2 ) the half $P$-curve test as well as the full $P$-curve test are right-skewed $(P<.10)$. Next, the application tests whether evidential value is inadequate or absent. To this end, the $P$-curve's right skew is compared to that of a $P$-curve that is powered at $33 \%$. Again, 2 conditions may be satisfied to indicate the inadequacy of evidential value for a real effect: 1 ) the full $P$-curve $33 \%$ power test is $P<.05$ or 2 ) the binomial as well as the continuous half $P$-curve $33 \%$ power test is significant at $P<.10$. Furthermore, while not formally tested by the application, a $P$ curve that shows no significant right skew and shows a left skew (more $P$ values above .25 than below) may indicate selective reporting within the examined studies. Finally, the application calculates the average power, underlying the statistical tests included in the analysis.

\section{Secondary Analyses}

According to Simonsohn et al, $^{70}$ a $P$-curve analysis should be conducted twice if there is some ambiguity as to whether a specific study or value should be included. One study, Faller et al, ${ }^{19}$ used presurgical scores on the Hospital Anxiety and Depression scale (HADS) to predict function postsurgery, but did not present separate results for depression and anxiety. Data from this study are relevant for analyses 4 and 7, which were therefore performed twice, once with and once without the data from Faller et al. ${ }^{19}$ The findings presented below include the results from Faller et al. ${ }^{19}$ The pattern of results did not differ between analyses including and excluding the results from Faller et al. ${ }^{19}$ Similarly, the study by Judge et $\mathrm{al}^{37}$ used the anxiety/depression subscale of the EQ-5D to predict pain and function postsurgery, relevant for analyses 4 through 7, which were therefore conducted twice. The findings presented below include the results from Judge et $\mathrm{al}^{37}$ and there were no differences in the results between their in- or exclusion.

\section{Study Quality Assessment}

The Methodological Index for Non-Randomized Studies (MINORS) ${ }^{77}$ was used to assess study quality. This tool has been found to be excellent in rating study quality for nonrandomized interventional studies, ${ }^{92}$ such as those involving surgical interventions. The MINORS comprises of 8 methodological items for nonrandomized studies that are scored as " 0 " for "not reported," "1" for "reported but inadequate," and " 2 " for "reported and adequate," hence study quality scores range from 0 to 16 . Study quality assessments were 
8 The Journal of Pain

completed independently by N.N. and S.C. for the final 26 studies. Agreement on the outcome was assessed through intraclass correlation. Differences in study quality assessments were resolved through discussion.

\section{Results}

\section{Main P-Curve Results}

Nine $P$-curve analyses were completed following the methods outlined above. For each analysis, the evidential value of the included $P$ values was first examined using the right-skew test. Next, to assess whether the $P$ values' evidential value was inadequate the $33 \%$ power test was used. An estimate of the average statistical power underlying the studies from which the $P$-values stem is finally presented including $90 \%$ confidence interval (Cls).

\section{Pre-surgical Psychological Factors on Postsurgical Outcomes}

A P-curve analysis was computed with data from all 26 studies to examine the evidential value of presurgical psychological predictors on function, wellbeing, analgesic consumption, and reported pain after surgery. The $P$ curve was significantly right skewed (full $P$-curve: $Z=$ $-5.01, P<.0001$; half $P$-curve: $Z=-4.99, P<.0001$ ), indicating that the $p$-values included in the analysis cumulatively contain evidential value (see Fig $2 A$ ). This was further supported by the absence of a left skew (Binomial test: $P=.7018$; Continuous tests: full $P$-curve: $Z=1.43, P=.9232$; half $P$-curve: $Z=6.25, P>.9999$ ), indicating that evidential value is not inadequate or absent. Therefore, there is no indication of ambitious $p$-hacking across predictors and outcomes. The statistical power of this analysis was estimated at $53 \%(90 \% \mathrm{Cl}=31-72 \%)$. Given that there were multiple values extracted from the same study in this analysis, the values mentioned first in the respective manuscripts were selected. We ran additional $P$-curve analyses including the omitted values to examine the robustness of the findings and found no differences in the pattern of results.

\section{Presurgical Psychological Factors on Function}

$P$-values from 14 studies were included in the examination of the evidential value underlying pre-surgical psychological predictors on function. Results indicate that the $P$ values included in this analysis contain evidential value, as supported by a significant right skew (full $P$-curve: $Z=-2.06, P=.0195$; half $P$-curve: $Z=$ $-2.89, P=.0019$; see Fig $2 B$ ). Similarly, the absence of a left skew indicates that evidential value is not inadequate or absent (Binomial test: $P=.3804$; Continuous tests: full $P$-curve: $Z=-.33, P=.371$; half $P$-curve: $Z=3.94, P>.9999)$, suggesting that there is no evidence of ambitious $p$-hacking in the investigation of presurgical psychological factors on post-surgical function overall. The statistical power of this analysis was estimated at $27 \%(90 \% \mathrm{Cl}=7-60 \%)$. We ran additional $P$-curve analyses including the omitted values to examine the robustness of the findings where there were multiple values extracted from the same study in this analysis and found no difference in the pattern of results.

\section{Presurgical Psychological Factors on Pain Intensity}

To investigate the evidential value of presurgical predictive factors on pain intensity, $P$-values from 16 studies were included in the analysis. The results showed a significant right skew (full $P$-curve: $Z=-6.88, P<.0001$; half $P$-curve: $Z=-5.1, P<.0001$; see Fig $2 \mathrm{C}$ ), indicating evidential value. This was further supported by the absence of a left skew (Binomial test: $P>$.9999; Continuous tests: full $P$-curve: $Z=3.72, P=.9999$; half $P$-curve: $Z=5.75, P>.9999)$, suggesting that evidential value is not inadequate or absent. Therefore, there is no indication of ambitious $p$-hacking across the examination of presurgical psychological factors on postsurgical pain. Finally, the power of the tests included in the analysis was estimated at $83 \%(90 \% \mathrm{Cl}=65-93 \%)$. Given that there were multiple values extracted from the same study in this analysis, the values mentioned first in the respective manuscripts were selected. We ran additional
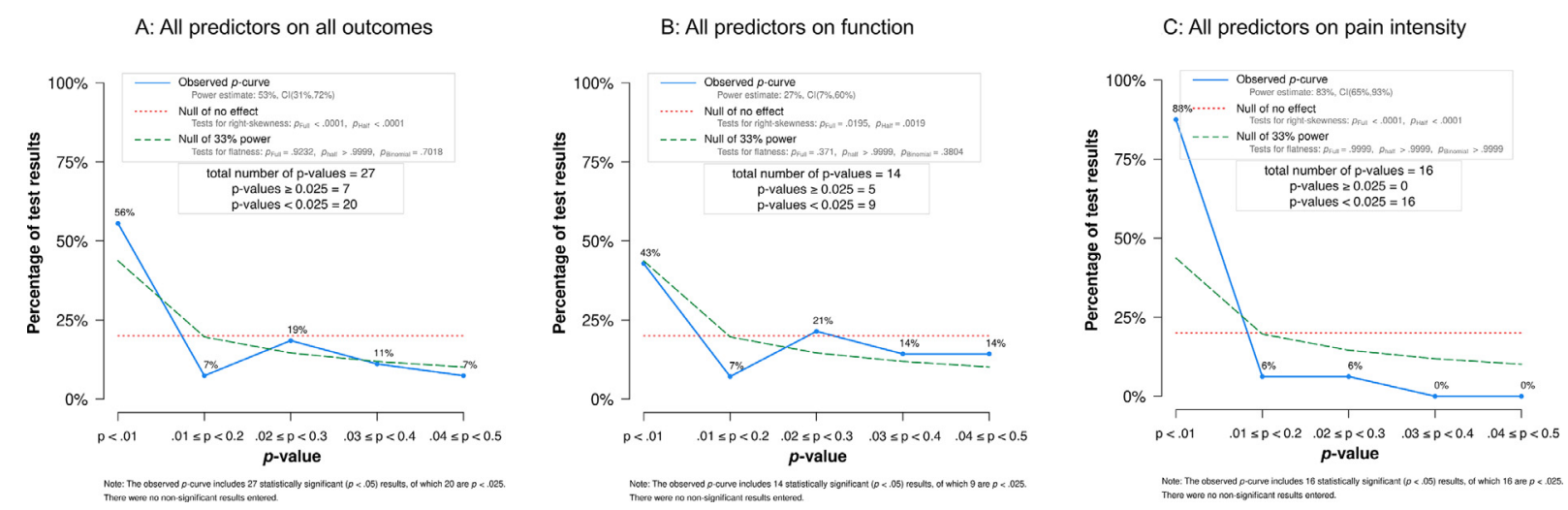

Figure 2. $P$-Curve analyses for the effects of all pre-surgical psychological predictor variables on all outcomes, pain intensity and function. All $P$-curve analyses indicated the existence of evidential value. Values listed at .01 represent the number of $P$-values smaller than .01 . Values listed at .02 represent the number of $P$-values between .01 and .02 , etc. 
Niederstrasser and Cook

$P$-curve analyses including the omitted values to examine the robustness of the findings and found no differences in the pattern of results.

\section{Depression on Function}

To examine the evidential value behind depression predicting function following arthroplasty, nine $P$-values were identified and included in the analysis. Results indicate that the $P$ values included in the analysis cumulatively contain evidential value as indicated by a significant right skew of the $P$-curve (full $P$-curve: $Z=-1.93, P=.0266$; half $P$-curve: $Z=-3.12, P=.0009$; see Fig $3 A$ ). This finding is supported by the absence of a left skew, which indicates that the evidential value is not inadequate or absent (Binomial test: $P=$ .507; Continuous tests: full $P$-curve: $Z=.05, P=.4788$; half $P$-curve: $Z=3.56, P=.9998)$. Therefore, there is no indication of ambitious $p$-hacking. Finally, power of the included tests was estimated at $32 \%(90 \% \mathrm{Cl}=7$ $-70 \%)$. Removal of the test statistics extracted from Faller et $\mathrm{al}^{19}$ and Judge et $\mathrm{al}^{37}$ did not meaningfully alter the results.

\section{Depression on Pain Intensity}

After entering 6 significant test statistics into the application, the results indicated that there is evidential value underlying the effect of presurgical depression levels on postsurgical pain intensity (full $P$-curve: $Z=$ -5.68, $P<.0001$; half $P$-curve: $Z=-4.92, P<.0001$, see Fig $3 \mathrm{~B}$ ). There was also no evidence indicative of a left skew in the distribution according to the Binomial test $(P>.999)$ and continuous $z$-tests (full $P$-curve: $Z=3.55$, $P=$.9998; half $P$-curve: $Z=4.53 P>$.9999), suggesting the absence of intense $p$-hacking and no lacking of evidential value. Finally, power of the included tests was estimated at $93 \%(90 \% \mathrm{Cl}=75-99 \%)$. Removal of the test statistics extracted from Judge et $\mathrm{al}^{37}$ did not meaningfully alter the results.

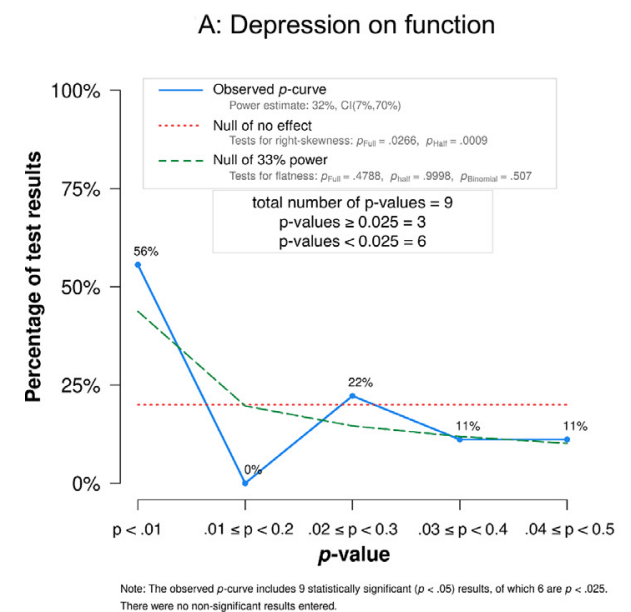

\section{Anxiety on Function}

The Journal of Pain

To test the evidential value underlying the effect of anxiety in predicting postsurgical function we included $8 P$ values in the analysis. The analysis suggests that there is evidential value underlying the association between presurgical anxiety and postsurgical function (full $P$-curve: $Z=-2.25, P=.0122$; half $P$-curve: $Z=-2.03$, $P=.021$; see Fig $4 A$ ). Evidential value is neither inadequate nor absent, and so there is no evidence of intense $p$-hacking an indicated by an absence of a left skew (Binomial test: $P=.4207$; Continuous tests: full $P$-curve: $Z=0.38, P=.6468$; half $P$-curve: $Z=2.84, P=.9977$ ). Finally, the power of the tests included in the analysis was estimated at $43 \%(90 \% \mathrm{Cl}=9-79 \%)$. Removal of the test statistics extracted from Faller et al $^{19}$ Judge et $\mathrm{al}^{37}$ did not meaningfully alter the results.

\section{Anxiety on Pain Intensity}

Ten statistically significant estimates were included in the analysis examining the evidential value underlying the effect of anxiety on postsurgical pain intensity. The results indicate that there is evidential value underlying the findings (full $P$-curve: $Z=-4.97, P<.0001$; half $p$-curve: $Z=-4.25, P<.0001$; see Fig 4B). Furthermore, there was no evidence of a left skew in the distribution according to the Binomial test $(P=.9668)$ and continuous $Z$-tests (full $P$-curve: $Z=2.54, P=.9944$; half $P$-curve: $Z=4.51, P>.9999)$, suggesting the absence of intense $p$-hacking and no lacking of evidential value. Finally, power of the included tests was estimated at $79 \%(90 \%$ $\mathrm{Cl}-51-93 \%)$. Removal of the test statistics extracted from Judge et $\mathrm{al}^{37}$ did not meaningfully alter the results.

\section{Pain Catastrophizing on Pain Intensity}

Three $P$ - values were examined for the presence of evidential value underlying the effect of pain catastrophizing predicting postsurgical pain intensity. The analysis revealed that there is evidential value

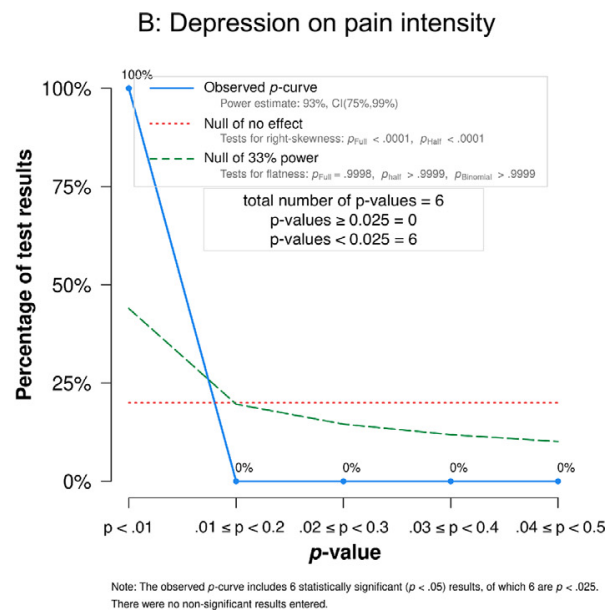

Figure 3. $P$-Curve analyses for the effects of depression on function and pain intensity. Both $P$-curve analyses indicated the existence of evidential value. Values listed at .01 represent the number of $P$-values smaller than .01 . Values listed at .02 represent the number of $P$-values between .01 and .02 , etc. 
A: Anxiety on function

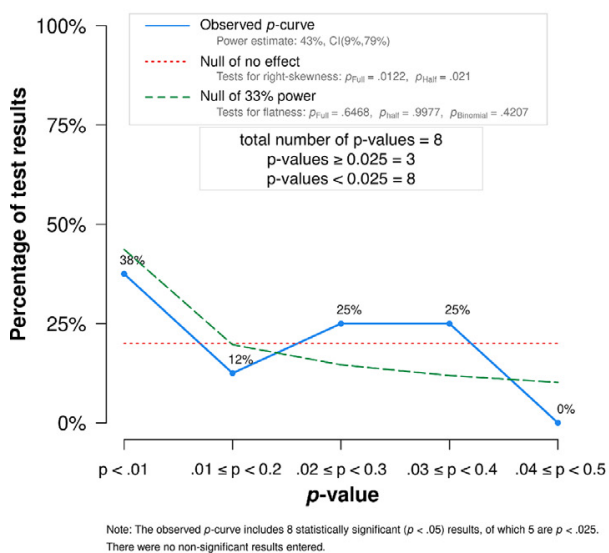

B: Anxiety on pain intensity

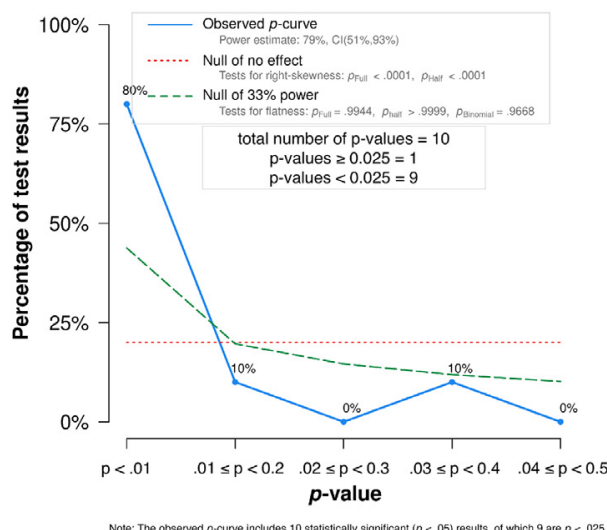

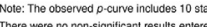

Figure 4. $P$-Curve analyses for the effects of anxiety on function and pain intensity. Both $P$-curve analyses indicated the existence of evidential value. Values listed at .01 represent the number of $P$-values smaller than .01 . Values listed at .02 represent the number of $P$-values between .01 and .02, etc.

underlying the relationship between presurgical pain catastrophizing and postsurgical pain intensity (full $p$-curve: $Z=-3.16, P=.0008$; half $P$-curve: $Z=-2.19$, $P=.0143$; see Fig 5). Evidential value is neither inadequate nor absent, and so there is no evidence of intense $p$-hacking an indicated by an absence of a left skew (Binomial test: $P>$.9999; Continuous tests: full $P$-curve: $Z=1.77, P=.9617$; half $P$-curve: $Z=2.68, P=.9963$ ). Finally, the power of the tests included in the analysis was estimated at $85 \%(90 \% \mathrm{Cl}=38-98 \%)$.

\section{Optimism on Pain Intensity}

Three $P$ values were included in the examination of the evidential value underlying the predictive properties of optimism on pain intensity. All $P$ values stem from results indicating a negative relationship between

Pain catastrophizing on pain intensity

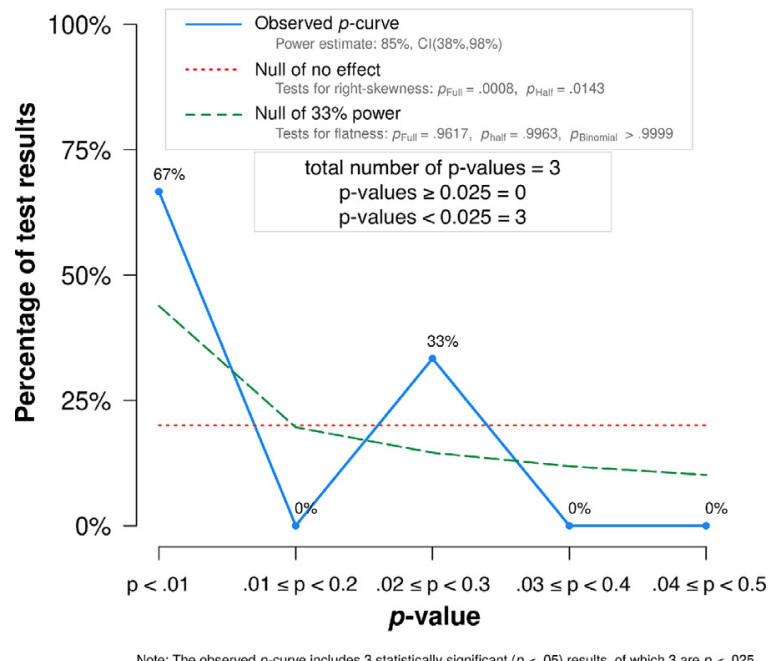

Note: The observed

Figure 5. $P$-Curve analysis for the effects of pain catastrophizing on pain intensity. The $P$-curve analysis indicated the existence of evidential value. Values listed at .01 represent the number of $P$-values smaller than .01 . Values listed at .02 represent the number of $P$-values between .01 and .02 , etc. optimism and pain intensity. The conditions for the presence of evidential value are not met (full $P$-curve: $Z=-2.15, P=.0157$; half $P$-curve: $Z=-1.24, P=.1071$, see Fig 6). Nevertheless, there is also no indication of a left skew, suggesting that evidential value is neither inadequate nor absent and there is no evidence of intense $p$-hacking (Binomial test: $P>$.9999; Continuous tests: full $P$-curve: $Z=0.90, P=.8151$; half $P$-curve: $Z=1.91$, $P=.9719)$. Finally, the power of the tests included in the analysis was estimated at $66 \%(90 \% \mathrm{Cl}=11-95 \%)$.

\section{Study Quality}

Study quality ranged from 12 to 16 and was overall adequate. Ratings for the individual studies are shown in Table 1 and there was a high level of agreement between raters (intraclass coefficient $=.94$ ).

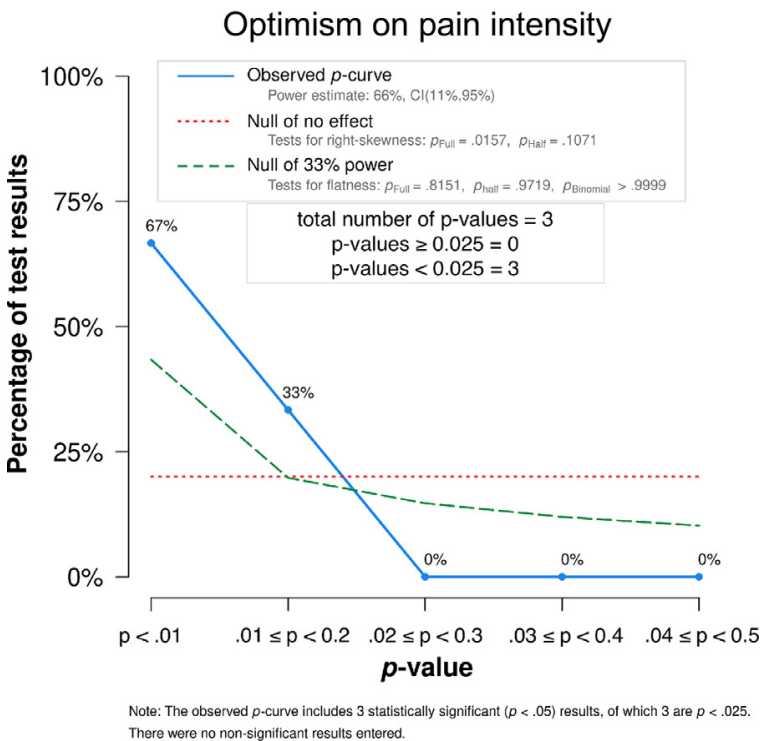

Figure 6. $P$-Curve analysis for the effects of optimism on pain intensity. The $P$-curve analysis indicated that the presence of evidential value could neither be confirmed nor rejected. Values listed at .01 represent the number of $P$-values smaller than .01 . Values listed at .02 represent the number of $P$-values between .01 and .02 , etc. 


\section{Discussion}

In this study, we found support for the presence of evidential value for all but one (optimism on pain intensity) of the examined sets of studies investigating the effect of presurgical psychological predictors on outcomes following knee and hip arthroplasty. This suggests that the reported significant results in themselves constitute evidence for the experimental hypotheses. The analyses indicated the presence of evidential value for the effect of depression on pain intensity and function, anxiety on pain intensity and function, pain catastrophizing on pain intensity, as well as the combined effects of all predictors on all outcomes, and all predictors on pain intensity and function respectively. In particular, our findings suggest that presurgical depression and anxiety are robust predictors of higher postsurgical pain and poor function. The findings highlight the importance of patients' psychological profiles in determining surgical success. Furthermore, the notion that selective reporting may be a likely explanation for these sets of statistically significant findings can be ruled out, as there were no signs of intense $p$-hacking underlying the reported effects for all examined sets of studies.

Depression and anxiety may negatively influence patients' motivation to engage in rehabilitation exercises and to overcome challenges in the recovery process and resume recreational, household, or social activities following surgery. ${ }^{26,79}$ This inactivity may lead to deconditioning, further arthritic degeneration and promote deteriorations in mood and health status. It has also been suggested that anxious patients tend to opt for surgery at a later time, when symptoms are more severe, ${ }^{8}$ increasing the likelihood of poor outcomes.

Psychosocial predictors may affect neurophysiological processes involved in pain modulation. ${ }^{14,24}$ For example, pain catastrophizing, depression, and anxiety have been linked with an increased sensitivity to pain. $31,34,57,67,81$ The resultant repeated painful stimulation may promote sensitization in the central nervous system by enacting neuroplastic changes in the spinal cord. ${ }^{27}$ Thus, these patients may find using pain medication to manage postsurgical pain less effective and repeated stimulations, such as during rehabilitation exercises, are experienced as increasingly painful, which makes patients less likely to engage in such exercises and remain sedentary. Furthermore, patients with certain psychological profiles, such as high levels of pain catastrophizing, anxiety, and depression may interpret surgery and repeated painful stimulations as more stressful. ${ }^{21,23,28,34,39,83}$ The subsequent stress response may hamper the healing process by promoting glucocorticoid release ${ }^{66}$ and suppressing lymphocyte circulation in the blood. ${ }^{15}$ Pain following surgery is inevitable, not just during rehabilitation exercises. This pain may elicit a greater stress response that prolongs the healing process and leads to a higher frequency of painful experiences following surgery.

While the set of $P$ values pertaining to the link between presurgical optimism and postsurgical pain intensity was right-skewed, neither condition necessary to indicate evidential value was met. Conversely, evidential value was also not inadequate, which suggests that the set of results are unlikely to be due to selective reporting. This does not imply that there is no association between presurgical optimism and postsurgical pain intensity, but rather that no definitive statement regarding the presence and magnitude of the evidential value can be made for the selected set of studies. The set of studies subject to this analysis included three studies from the same primary author. ${ }^{53-55}$ Reasons for the inconclusiveness of the results may be rooted in the low number of studies and observations within studies. Thus, these results should be viewed with caution. Furthermore, the nature of the results may stem from combining results for total hip arthroplasty (THA) and total knee arthroplasty (TKA). One study ${ }^{54}$ reported results separately for THA and TKA, while two ${ }^{53,55}$ did not differentiate between hip and knee arthroplasty. In the case of THA, optimism did not predict outcomes following surgery, ${ }^{54}$ and so it is possible that the link between optimism and pain intensity varies between knee and hip arthroplasty. Results combining both sites may therefore lead to higher $P$ values, obscuring the true evidential value. Future studies should further investigate the presence of surgery-specific effects. Lastly, optimism was quantified as a trait in these investigations and may be more predictive when operationalized as outcome expectancy specific to surgery. ${ }^{49}$

$p$-Curve analysis allows the distinction between sets of findings that are likely and unlikely to suffer from selective reporting. ${ }^{70}$ Therefore, the absence of evidential value of a specific set of results does not imply that the theory proposed to underlie the significant results is wrong. $P$-Curve examines the reported data and not the theory and therefore itself is susceptible to noise, sample sizes, and other biases. ${ }^{70}$ The levels of power estimated for the sets of studies suggest that the majority of studies are not adequately powered. In particular the main $P$-curve analysis revealed a power estimate of $53 \%$ $(90 \% \mathrm{Cl}=31-72 \%)$. Low to medium levels of statistical power may help explain the presence of null results in the literature. Similarly, it should be noted that only published studies were examined, potential high-quality studies were possibly excluded due not reporting relevant test statistics, and the search was limited to 2 data bases. Thus, publication bias may have influenced the nature of the findings. Most of the included studies examined links of anxiety and depression with pain and function. Only a single eligible study reported test statistics for a quality of life outcome and few others for the links of pain catastrophizing and optimism with outcomes. While caution is warranted when interpreting our study's findings, we used a disclosure table and preregistered the study details to limit the influence of biases. Differences in methodology, timing of assessments, and assessment tools may also have affected results. For example, timing of postsurgical assessment ranged from 48 hours to up to 5 years. Assessments also varied; for depression, among others, the HADS and the EQ-D5 were used. Furthermore, current reporting 
12 The Journal of Pain

practices precluded the inclusion of several relevant studies, as essential test statistics were not provided, tis, hat no exact $P$ values or associated test statistics. This reiterates the importance of conducting $P$-curve analyses, as such practices may be a naÿve form of selective reporting. We recommend that authors aim to disclose exact $P$ values and all relevant test statistics in the future in order to ameliorate this issue.

The presence of evidential value for associations between presurgical psychological variables and postsurgical outcomes may represent a relevant avenue to consider when developing novel treatments to improve arthroplasty. There is a clear need to identify those at risk for increased disability and pain following knee replacement surgery to deliver preventative measures or explore alternative care. In particular, presurgical pain catastrophizing, depression, and anxiety may present risk factors for poor outcomes following primary joint arthroplasty. It has been shown repeatedly that these risk factors predict unique chunks of variance in outcome factors, even when strong relationships between, for example, preoperative and postoperative pain intensity are controlled for. ${ }^{50,80,85}$ Awareness and subsequent treatment of such presurgical states may help to prevent debilitating pain and/or disability following surgery. Chronic OA-pain is exceedingly common with roughly 1 of 5 people in the UK 45 and older having sought treatment for knee-OA. Future predictions estimate that by 2035, there will be 8.3 million knee-OA sufferers alone, aged 45 and over in the UK, ${ }^{2}$ highlighting the importance of this subject area. Up to

\section{References}

1. Abrecht CR, Cornelius $M$, Wu A, Jamison RN, Janfaza D, Urman RD, Campbell C, Smith M, Haythornthwaite J, Edwards RR, Schreiber KL: Prediction of pain and opioid utilization in the perioperative period in patients undergoing primary knee arthroplasty: Psychophysical and psychosocial factors. Pain Med 20:161-171, 2019

2. Arthritis Research UK: Osteoarthritis in General Practice. Med Press, 2013, pp 1-36

3. Balck F, Lippmann M, Jeszenszky C, Günther KP, Kirschner S: The influence of optimism on functionality after total hip replacement surgery. J Health Psychol 21:1758-1767, 2016

4. Banka TR, Ruel A, Fields K, YaDeau J, Westrich G: Preoperative predictors of postoperative opioid usage, pain scores, and referral to a pain management service in total knee arthroplasty. HSS J 11:71-75, 2015

5. Becker N, Bondegaard Thomsen A, Olsen AK, Sjøgren P, Bech P, Eriksen J: Pain epidemiology and health related quality of life in chronic non-malignant pain patients referred to a Danish multidisciplinary pain center. Pain 73:393-400, 1997

6. Benditz A, Jansen P, Schaible J, Roll C, Grifka J, Götz J: Psychological factors as risk factors for poor hip function after total hip arthroplasty. Ther Clin Risk Manag 13:237-244, 2017

7. Beswick AD, Wylde V, Gooberman-Hill R, Blom A, Dieppe $P$ : What proportion of patients report long-term pain after
A p-Curve Analysis

$30 \%$ of these patients will develop increased pain and disability, despite objective indicators of surgical success $^{7,17,51}$ and presurgical psychological profiles might help identify those at risk of developing these adverse outcomes. Further research into presurgical preventative measures addressing psychological factors such as anxiety and depression is therefore a worthy cause.

To summarize, we confirmed the presence of evidential value for sets of studies examining the effects of psychosocial factors on outcomes following TKA and THA. In particular, presurgical anxiety, depression and pain catastrophizing appear to be robust predictors of higher postsurgical pain and poor functioning. Our findings could not confirm that there was evidential value underlying the link between presurgical optimism and postsurgical pain intensity for the current set of studies. Nevertheless, the link does not appear to be attributable to selective reporting, but rather, a small amount of studies investigating the relationship which do not separate findings for THA and TKA. Given the restrictions imposed by the nature of the analysis, the scarcity of relevant studies, and reporting restrictions, not all desired predictor-outcome relationships could be examined. Authors should aim to report exact $P$ values and relevant statistics in order to avoid such issues in future investigations of this kind. Presurgical psychosocial factors inevitably have an effect on recovery, pain, and function postsurgery, and should be considered as risk factors which medical professionals may wish to address using preventative measures.

total hip or knee replacement for osteoarthritis? A systematic review of Prospective studies in unselected patients. BMJ Open 2:e000435, 2012

8. Bierke S, Petersen W: Influence of anxiety and pain catastrophizing on the course of pain within the first year after uncomplicated total knee replacement: a prospective study. Arch Orthop Trauma Surg 137:17351742, 2017

9. Blackburn J, Qureshi A, Amirfeyz R, Bannister G: Does preoperative anxiety and depression predict satisfaction after total knee replacement? Knee 19:522-524, 2012

10. Bossmann T, Brauner T, Wearing S, Horstmann T: Predictors of chronic pain following total knee replacement in females and males: an exploratory study. Pain Manag 7:391-403, 2017

11. Brander V, Gondek S, Martin E, Stulberg SD: The John Insall award: Pain and depression influence outcome 5 years after knee replacement surgery. Clin Orthop Relat Res 464:21-26, 2007

12. Brembo EA, Kapstad H, Van Dulmen S, Eide H: Role of self-efficacy and social support in short-term recovery after total hip replacement: a prospective cohort study. Health Qual Life Outcomes 15:68, 2017

13. Burns LC, Ritvo SE, Ferguson MK, Clarke H, Seltzer Z, Katz J: Pain catastrophizing as a risk factor for chronic pain after total knee arthroplasty: A systematic review. J Pain Res 8:21-32, 2015 
Niederstrasser and Cook

14. Campbell CM, Edwards RR: Mind-body interactions in pain: the neurophysiology of anxious and catastrophic pain-related thoughts. Transl Res 153:97-101, 2009

15. Dhabhar FS, Malarkey WB, Neri E, McEwen BS: Stressinduced redistribution of immune cells-From barracks to boulevards to battlefields: A tale of three hormones - Curt Richter Award Winner. Psychoneuroendocrinology 37:1345-1368, 2012

16. Duivenvoorden T, Vissers MM, Verhaar JAN, Busschbach JJV, Gosens T, Bloem RM, Bierma-Zeinstra SMA, Reijman $M$ : Anxiety and depressive symptoms before and after total hip and knee arthroplasty: A prospective multicentre study. Osteoarthr Cartil 21:1834-1840, 2013

17. Dunbar MJ, Richardson G, Robertsson O: I can't get no satisfaction after my total knee replacement: rhymes and reasons. Bone Joint J 95:148-152, 2013

18. Engel C, Hamilton NA, Potter PT, Zautra AJ: Impact of two types of expectancy on recovery from Total Knee Replacement surgery (TKR) in adults with osteoarthritis. Behav Med 30:113-123, 2004

19. Faller $H$, Kirschner $S$, König A: Psychological distress predicts functional outcomes at three and twelve months after total knee arthroplasty. Gen Hosp Psychiatry 25:372373,2003

20. Filardo G, Merli G, Roffi A, Marcacci T, Berti Ceroni F, Raboni D, Bortolotti B, Kon E, Marcacci M: Kinesiophobia and depression affect total knee arthroplasty outcome in a multivariate analysis of psychological and physical factors on 200 patients. Knee Surg Sport Traumatol Arthrosc 25:3417-3423, 2017

21. Flanigan DC, Everhart JS, Glassman AH: Psychological factors affecting rehabilitation and outcomes following elective orthopaedic surgery. J Am Acad Orthop Surg 23:563-570, 2015

22. Forsythe ME, Dunbar MJ, Hennigar AW, Sullivan MJL, Gross M: Prospective relation between catastrophizing and residual pain following knee arthroplasty: Two-year follow-up. Pain Res Manag 13:335-341, 2008

23. France $C R$, France $J L$, Absi M, Ring C, Mclntyre D: Catastrophizing is related to pain ratings, but not nociceptive flexion reflex threshold. Pain 99:459-463, 2002

24. Garland EL: Pain processing in the human nervous system. A selective review of nociceptive and biobehavioral pathways. Prim Care Clin Off Pract 39:561-571, 2012

25. Giner-Sorolla R: Science or art? how aesthetic standards grease the way through the publication bottleneck but undermine science. Perspect Psychol Sci 7:562-571, 2012

26. Gonzalez MJ, Miranda-Massari JR, Berdiel MJ, Duconge J, Rodríguez-López JL, Hunninghake R, Cobas-Rosario VJ: High dose intraveneous Vitamin C and chikungunya fever: A case report. J Orthomol Med 29:154-156, 2014

27. Goodin BR, McGuire L, Allshouse M, Stapleton L, Haythornthwaite JA, Burns N, Mayes LA, Edwards RR: Associations between catastrophizing and endogenous paininhibitory processes: Sex differences. J Pain 10:180-190, 2009

28. Hannibal KE, Bishop MD: Chronic stress, cortisol dysfunction, and pain: a psychoneuroendocrine rationale for
The Journal of Pain 13

stress management in pain rehabilitation. Phys Ther 94:1816-1825, 2014

29. Hanusch BC, O'Connor DB, lons $P$, Scott A, Gregg PJ: Effects of psychological distress and perceptions of illness on recovery from total knee replacement. Bone Jt J 96:210216,2014

30. Head ML, Holman L, Lanfear R, Kahn AT, Jennions MD: The extent and consequences of p-hacking in science. PLoS Biol Public Library of Science 13:e1002106, 2015

31. Hermesdorf $M$, Berger $K$, Baune BT, Wellmann J, Ruscheweyh R, Wersching H: Pain sensitivity in patients with major depression: Differential effect of pain sensitivity measures, somatic cofactors, and disease characteristics. J Pain 17:606-616, 2016

32. Hernández C, Díaz-Heredia J, Berraquero ML, Crespo $\mathrm{P}_{\text {, }}$ Loza E, MÁ Ruiz Ibán: Factores predictores prequirúrgicos de dolor posquirúrgico en pacientes sometidos a artroplastia de cadera o rodilla. Una revisión sistemática. Reumatol Clin 11:361-380, 2015

33. Hirschmann MT, Testa E, Amsler F, Friederich NF: The unhappy total knee arthroplasty (TKA) patient: Higher WOMAC and lower KSS in depressed patients prior and after TKA. Knee Surgery, Sport Traumatol Arthrosc 21:2405-2411, 2013

34. Hirsh AT, George SZ, Bialosky JE, Robinson ME: Fear of pain, pain catastrophizing, and acute pain perception: relative prediction and timing of assessment. J Pain 9:806-812, 2008

35. Hiyama Y, Wada O, Nakakita S, Mizuno K: Factors affecting mobility after knee arthroplasty. J Knee Surg 30:304-348, 2017

36. Johnson VE, Payne RD, Wang T, Asher A, Mandal S: On the reproducibility of psychological science. J Am Stat Assoc American Association for the Advancement of Science $112: 1-10,2017$

37. Judge A, Arden NK, Cooper C, Javaid MK, Carr AJ, Field RE, Dieppe PA: Predictors of outcomes of total knee replacement surgery. Rheumatol 51:1804-1813, 2012

38. Kagan MA, RN I, Bar-Tal Y: The effect of preoperative uncertainty and anxiety on short- term recovery after elective arthroplasty. J Clin Nurs 17:576, 2008

39. Keefe FJ, Caldwell DS, Martinez S, Nunley J, Beckham J, Williams DA: Analyzing pain in rheumatoid arthritis patients. Pain coping strategies in patients who have had knee replacement surgery. Pain 46:153-160, 1991

40. Khatib Y, Madan A, Naylor JM, Harris IA: Do Psychological factors predict poor outcome in patients undergoing TKA? a systematic review. Clin Orthop Relat Res 473:26302638,2015

41. Kocic M, Stankovic A, Lazovic M, Dimitrijevic L, Stankovic I, Spalevic M, Stojiljkovic P, Milenkovic M, Stojanovic Z, Nikolic D: Influence of fear of movement on total knee arthroplasty outcome. Ann Ital Chir 86:148-155, 2015

42. Kornilov N, Lindberg MF, Gay C, Saraev A, Kuliaba T, Rosseland LA, Muniz K, Lerdal A: Factors related to postoperative pain trajectories following total knee arthroplasty: A longitudinal study of patients admitted to a Russian orthopaedic clinic. Pain Res Treat 2016:1-12, 2016 


\section{The Journal of Pain}

43. Kunda Z: The case for motivated reasoning. Psychol Bull 108:480-498, 1990

44. Langlois J, Charles-Nelson A, Katsahian S, Beldame J, Lefebvre B, Bercovy M: Predictors of flexion using the rotating concave-convex total knee arthroplasty: preoperative range of motion is not the only determinant. Knee surgery. Sport Traumatol Arthrosc 23:1734-1740, 2015

45. Lewis GN, Rice DA, McNair PJ, Kluger M: Predictors of persistent pain after total knee arthroplasty: A systematic review and meta-analysis. Br J Anaesth 114:551-561, 2015

46. Lindner M, Nosseir $O$, Keller-Pliessnig A, Teigelack $P$, Teufel M, Tagay S: Psychosocial predictors for outcome after total joint arthroplasty: A prospective comparison of hip and knee arthroplasty. BMC Musculoskelet Disord 19:19, 2018

47. Lopez-Olivo MA, Landon GC, Siff SJ, Edelstein D, Pak C, Kallen MA, Stanley M, Zhang H, Robinson KC, Suarez-Almazor ME: Psychosocial determinants of outcomes in knee replacement. Ann Rheum Dis 70:1775-1781, 2011

48. Luna IE, Kehlet H, Petersen MA, Aasvang EK: Clinical, nociceptive and psychological profiling to predict acute pain after total knee arthroplasty. Acta Anaesthesiol Scand 61:676-687, 2017

49. Mannion AF, Kämpfen S, Munzinger U, Kramers-de Quervain I: The role of patient expectations in predicting outcome after total knee arthroplasty. Arthritis Res Ther 11:R139, 2009

50. McHugh GA, Campbell M, Luker KA: Predictors of outcomes of recovery following total hip replacement surgery: A prospective study. Bone Joint Res 2:248-254, 2013

51. Noble PC, Conditt MA, Cook KF, Mathis KB: The John Insall Award: Patient expectations affect satisfaction with total knee arthroplasty. Clin Orthop Relat Res 452:35-43, 2006

52. Noiseux NO, Callaghan JJ, Clark CR, Zimmerman MB, Sluka KA, Rakel BA: Preoperative predictors of pain following total knee arthroplasty. J Arthroplasty 29:1383-1387, 2014

53. Pinto PR, Mclntyre T, Araújo-Soares V, Costa P, Almeida $A$ : Differential predictors of acute post-surgical pain intensity after abdominal hysterectomy and major joint arthroplasty. Ann Behav Med 49:384-397, 2015

54. Pinto PR, Mclntyre T, Araújo-Soares V, Costa P, Ferrero $\mathrm{R}$, Almeida A: A comparison of predictors and intensity of acute postsurgical pain in patients undergoing total hip and knee arthroplasty. J Pain Res 10:1087-1098, 2017

55. Pinto PR, Mclntyre T, Ferrero R, Almeida A, AraújoSoares V: Predictors of acute postsurgical pain and anxiety following primary total hip and knee arthroplasty. J Pain $14: 502-515,2013$

56. Rakel BA, Blodgett NP, Bridget Zimmerman M, Logsden-Sackett N, Clark C, Noiseux N, Callaghan J, Herr K, Geasland K, Yang X, Sluka KA: Predictors of postoperative movement and resting pain following total knee replacement. Pain 153:2192-2203, 2012

57. Rhudy JL, Meagher MW: Fear and anxiety: Divergent effects on human pain thresholds. Pain 84:65-75, 2000
A p-Curve Analysis

58. Rice DA, Kluger MT, McNair PJ, Lewis GN, Somogyi AA, Borotkanics R, Barratt DT, Walker M: Persistent postoperative pain after total knee arthroplasty: a prospective cohort study of potential risk factors. Br J Anaesth 121:804-812, 2018

59. Riddle DL, Perera RA, Nay WT, Dumenci L: What is the relationship between depressive symptoms and pain during functional tasks in persons undergoing TKA? A 6-year perioperative cohort study. Clin Orthop Relat Res 473:35273534, 2015

60. Riddle DL, Wade JB, Jiranek WA, Kong X: Preoperative pain catastrophizing predicts pain outcome after knee arthroplasty. Clin Orthop Relat Res 468:798-806, 2010

61. Rolfson O, Dahlberg LE, Nilsson J-A, Malchau H, Garellick G: Variables determining outcome in total hip replacement surgery. J Bone Jt Surg 91:157-161, 2009

62. Rosenthal R: The file drawer problem and tolerance for null results. Psychol Bull 86:638-641, 1979

63. Roth $\mathrm{ML}$, Tripp DA, Harrison $\mathrm{MH}$, Sullivan $\mathrm{M}$, Carson $\mathrm{P}$ : Demographic and psychosocial predictors of acute perioperative pain for total knee arthroplasty. Pain Res Manag $12: 185-194,2007$

64. Salmon P, Hall GM, Peerbhoy D: Influence of the emotional response to surgery on functional recovery during 6 months after hip arthroplasty. J Behav Med 24:489-502, 2001

65. Sanchez-Santos MT, Garriga C, Judge A, Batra RN, Price AJ, Liddle AD, Javaid MK, Cooper C, Murray DW, Arden NK: Development and validation of a clinical prediction model for patient-reported pain and function after primary total knee replacement surgery article. Sci Rep 8:1-9, 2018

66. Schäcke H, Döcke WD, Asadullah K: Mechanisms involved in the side effects of glucocorticoids. Pharmacol Ther 96:23-43, 2002

67. Schumacher R, Velden M: Anxiety, pain experience, and pain report: a signal-detection study. Percept Mot Skills 58:339-349, 1984

68. Schwartz FH, Lange J: Factors that affect outcome following total joint arthroplasty: A review of the recent literature. Curr Rev Musculoskelet Med 10:346-355, 2017

69. Simmons JP, Nelson LD, Simonsohn U: False-positive psychology: Undisclosed flexibility in data collection and analysis allows presenting anything as significant. Psychol Sci 22:1359-1366, 2011

70. Simonsohn U, Nelson LD, Simmons JP: P-curve: A key to the file-drawer. J Exp Psychol Gen 143:534-547, 2014

71. Simonsohn U, Nelson LD, Simmons JP: P-curve and effect size: correcting for publication bias using only significant results. Perspect Psychol Sci 9:666-681, 2014

72. Simonsohn U, Simmons JP, Nelson LD: Better p-curves: Making p-curve analysis more robust to errors, fraud, and ambitious p-hacking, a reply to Ulrich and Miller (2015). J Exp Psychol Gen 144:1146-1152, 2015

73. Singh JA, Lewallen D: Predictors of pain and use of pain medications following primary Total Hip Arthroplasty (THA): 5,707 THAs at 2-years and 3,289 THAs at 5-years. BMC Musculoskelet Disord 11:1-8, 2010 
Niederstrasser and Cook

74. Singh JA, Lewallen DG: Medical and psychological comorbidity predicts poor pain outcomes after total knee arthroplasty. Rheumatol 52:916-923, 2013

75. Singh JA, Lewallen DG: Predictors of activity limitation and dependence on walking aids after primary total hip arthroplasty. J Am Geriatr Soc 58:2387-2393, 2010

76. Singh JA, Lewallen DG: Predictors of use of pain medications for persistent knee pain after primary total knee arthroplasty: A cohort study using an institutional joint registry. Arthritis Res Ther 14:R248, 2012

77. Slim K, Nini E, Forestier D, Kwiatkowski F, Panis Y, Chipponi J: Methodological index for non-randomized studies (Minors): Development and validation of a new instrument. ANZ J Surg 73:712-716, 2003

78. Sobol-Kwapinska M, Bąbel P, Plotek W, Stelcer B: Psychological correlates of acute postsurgical pain: A systematic review and meta-analysis. Eur J Pain 20:1573-1586, 2016

79. Sullivan M, Tanzer M, Reardon G, Amirault D, Dunbar M, Stanish W: The role of presurgical expectancies in predicting pain and function one year following total knee arthroplasty. Pain 152:2287-2293, 2011

80. Sullivan M, Tanzer M, Stanish W, Fallaha M, Keefe FJ, Simmonds M, Dunbar M: Psychological determinants of problematic outcomes following total knee arthroplasty. Pain 143:123-129, 2009

81. Sullivan MJL, Thorn B, Haythornthwaite JA, Keefe F, Martin M, Bradley LA, Lefebvre JC: Theoretical perspectives on the relation between catastrophizing and pain. Clin J Pain 17:52-64, 2001

82. Szucs D, loannidis JPA: Empirical assessment of published effect sizes and power in the recent cognitive neuroscience and psychology literature Wagenmakers E-J, editor PLoS Biol Public Library of Science 15:e2000797, 2017

83. Tang J, Gibson SJ: A psychophysical evaluation of the relationship between trait anxiety, pain perception, and induced state anxiety. J Pain 6:612-619, 2005

84. Thomazeau J, Rouquette A, Martinez V, Rabuel C, Prince N, Laplanche JL, Nizard R, Bergmann JF, Perrot S,
The Journal of Pain 15

Lloret-Linares C: Acute pain Factors predictive of postoperative pain and opioid requirement in multimodal analgesia following knee replacement. Eur J Pain 20:822-832, 2016

85. Thomazeau J, Rouquette A, Martinez V, Rabuel C, Prince N, Laplanche JL, Nizard R, Bergmann JF, Perrot S, Lloret-Linares C: Predictive factors of chronic post-surgical pain at 6 months following knee replacement: Influence of postoperative pain trajectory and genetics. Pain Physician 19:729-741, 2016

86. Van Den Akker-Scheek I, Stevens M, Groothoff JW, Bulstra SK, Zijlstra W: Preoperative or postoperative self-efficacy: Which is a better predictor of outcome after total hip or knee arthroplasty? Patient Educ Coun 66:92-99, 2007

87. Vissers MM, Bussmann JB, Verhaar JAN, Busschbach JJ V, Bierma-Zeinstra SMA, Reijman M: Psychological factors affecting the outcome of total hip and knee arthroplasty: A systematic review. Semin Arthritis Rheum 41:576-588, 2012

88. Wylde V, Dixon S, Blom AW: The role of preoperative self-efficacy in predicting outcome after total knee replacement. Musculoskeletal Care 10:110-118, 2012

89. Wylde V, Trela-Larsen L, Whitehouse MR, Blom AW: Preoperative psychosocial risk factors for poor outcomes at 1 and 5 years after total knee replacement: A cohort study of 266 patients. Acta Orthop 88:530-536, 2017

90. Yakobov E, Scott W, Stanish W, Dunbar M, Richardson G, Sullivan M: The role of perceived injustice in the prediction of pain and function after total knee arthroplasty. Pain 155:2040-2046, 2014

91. Yakobov E, Stanish W, Tanzer M, Dunbar M, Richardson G, Sullivan MJL: The prognostic value of pain catastrophizing in health-related quality of life judgments after total knee arthroplasty. Health Qual Life Outcomes 16:126-134, 2018

92. Zeng $X$, Zhang $Y$, Kwong JSW, Zhang C, Li S, Sun F, Niu $Y$, Du L: The methodological quality assessment tools for preclinical and clinical studies, systematic review and metaanalysis, and clinical practice guideline: A systematic review. J Evid Based Med 8:2-10, 2015 